\title{
Avaliação Independente de Projectos EQUAL. Reflexões e propostas a partir de uma experiência
}

\author{
João Emílio Alves * \\ Eva Marques Milheiro ** \\ Alexandre Cotovio Martins ***
}

\begin{abstract}
$\mathrm{R}$ esumo: Atendendo às especificidades do Programa EQUAL na sua globalidade e à diversidade de projectos financiados no seu âmbito (muitos deles diferentes e singulares no que respeita, por exemplo, às metodologias e processos de execução nos respectivos territórios), apresenta-se neste artigo um conjunto de considerações de índole teórico-metodológica sobre os processos de avaliação independente dirigidos aos mesmos projectos. Partindo de uma experiência de avaliação independente, retoma-se aqui o dispositivo de avaliação elaborado e aplicado, o qual procurou incorporar e materializar um conjunto de referenciais teóricos e metodológicos habituais em processos de avaliação, a partir das orientações bibliográficas disponíveis (parte delas sugeridas inclusivamente pelo Gabinete de Gestão EQUAL). Descrevem-se adicionalmente as opções pela elaboração de um sistema de avaliação com recurso a várias metodologias e técnicas, numa perspectiva articulada entre procedimentos e instrumentos de cariz quantitativo e qualitativo, ajustados às especificidades do projecto em avaliação, no sentido de proporcionar uma reflexão, tão rigorosa quanto útil, para a respectiva Parceria de Desenvolvimento (PD). É sobre as características e potencialidades desse dispositivo, acompanhado por alguns dados empíricos a título de ilustração, que se dá conta no presente texto.
\end{abstract}

Palavras-chave: Avaliação; Avaliação independente; Programa EQUAL; Parceria de desenvolvimento; Equipas-recurso.

\section{Os processos de avaliação (independente) face às especificidades do Programa EQUAL}

Um vector cada vez mais importante associado aos projectos e programas de desenvolvimento e intervenção social passa pela elaboração e monitorização de dispositivos de avaliação. Neste contexto, quando falamos de avaliação referimo-nos, não a reflexões espontâneas e intuitivas, mas a processos de ordem científica que procuram enfatizar a objectividade, a recolha de informações e de dados necessários para alcançar resultados válidos, sistemáticos e fiáveis, mediante a concepção e implementação de métodos e técnicas de avaliação rigorosos, a par da construção de um quadro de dimensões de análise e de indicadores capazes de permitirem realizar balanços e observações avaliativas, com importância e utilidade para a compreensão dos próprios processos, quer se tratem de políticas, programas, medidas ou projectos.

Não existindo uma definição exclusiva de avaliação, subsistindo, antes pelo contrário, várias propostas teóricas e metodológicas diferentes ou complementares, recupera-se e sintetiza-se aqui uma interpretação possível, a qual será tomada doravante como indicação nuclear no contexto deste texto, com base num conjunto de reflexões resultantes de um processo de avaliação externa

\footnotetext{
* Sociólogo, mestre em Sociologia, domínio de aplicação em Cidade, Território e Requalificação e docente na Escola Superior de Educação do Instituto Politécnico de Portalegre.Contacto: joão.emilio@mail.esep.ipportalegre.pt; joaoemilioalves@gmail.com

** Licenciada em Gestão e Planeamento em Turismo, mestre em Gestão de Informação e docente na Escola Superior de Educação do Instituto Politécnico de Portalegre.Contacto: eva@esep.pt; emilheiro@yahoo.com

*** Sociólogo, mestre em Sociologia, domínio de aplicação em Cidade, Território e Requalificação e docente na Escola Superior de Educação do Instituto Politécnico de Portalegre. Contacto: alxmiguele@gmail.com
} 
independente, dirigido a um projecto EQUAL, realizado nos últimos dois anos ${ }^{2}$. Neste sentido, as expressões avaliação e metodologias de avaliação remetem então para "processos de pesquisa científica que visam deliberadamente colocar questões relativas à concepção, às formas de tomada de decisão, à execução e aos efeitos de programas, políticas, projectos e investimentos, quer dizer, de diferentes dispositivos criados para modificar situações e resolver problemas. Tais processos socorrem-se de sistemas de reflexão crítica a partir de informações recolhidas no decurso do acompanhamento ou após a conclusão desses dispositivos, de modo a permitir que as pessoas e as instituições envolvidas julguem o seu trabalho e aprendam com os julgamentos feitos" (Capucha, Almeida e Pedroso, 1996:9).

Tendo em conta este entendimento a respeito do significado, importância e validade dos processos de avaliação, e especificamente no quadro do processo de avaliação externa independente levado a cabo em relação ao projecto mencionado, julgou-se pertinente e necessário para uma percepção mais exigente do mesmo projecto em avaliação, conhecer, caracterizar e tipificar as intervenções, as dinâmicas e os graus de convergência e divergência manifestados pelos actores sociais implicados. $\mathrm{O}$ conhecimento destes indicadores, pode revelar-se (como efectivamente veio a acontecer) uma fonte de informação determinante para a sistematização e compreensão das dinâmicas, dos processos, dos impactes esperados e concretizados com a implementação do referido projecto, em estreita articulação com as próprias auto-avaliações produzidas pela respectiva parceria de desenvolvimento (PD) inerente ao mesmo projecto.

Associados a esta perspectiva analítica, a respeito do conceito de avaliação, e especificado o sentido da mesma, os objectivos que normalmente presidem à concepção, montagem e implementação de sistemas e dispositivos de avaliação podem passar pelas respostas possíveis às seguintes interrogações: avaliar o quê? e avaliar para quê?

Uma das respostas pode passar pela assunção de que a avaliação serve fundamentalmente para "melhorar a qualidade das intervenções" (Capucha,
1999), independentemente do seu âmbito, sobretudo nas temáticas relacionadas com o desenvolvimento social, a educação, a formação profissional, os programas de desenvolvimento nacional, regional e local, entre outras.

Decorrentes desta perspectiva, os diferentes tipos e processos de avaliação que se podem conceber e implementar, tendo em conta as especificidades dos domínios de aplicação enumerados atrás, produzem, em geral, diferentes resultados, conhecimentos e aprendizagens, sendo possível, no entanto, identificar um conjunto de contributos fundamentais e transversais a todos eles.

Esses contributos podem dirigir-se para a procura de respostas que visem: a melhoria do autoconhecimento das organizações e das intervenções, dando conta do funcionamento das instituições, projectos e programas, identificando os níveis de cumprimento dos seus objectivos, a forma de utilização dos recursos e as suas potencialidades de desenvolvimento; $\mathrm{o}$ aperfeiçoamento dos processos de tomada de decisão, a par da definição de prioridades e de rentabilização de recursos, fornecendo, desta feita, informações que podem ser relevantes para os decisores; a produção de informações sistematizadas sobre os dispositivos de intervenção, funcionando como meio de difusão da informação e de eventual reprodução dos aspectos inovadores de uma intervenção, contrariando a tendência, por vezes existente, das instituições e de parceiros trabalharem de costas voltadas, sem terem conhecimento recíproco do trabalho desenvolvido; a promoção de uma cultura de diálogo, através do intercâmbio de ideias e de aprendizagem colectiva, estimulando a participação dos vários actores envolvidos nas intervenções, nomeadamente técnicos e beneficiários; e por fim, o desenvolvimento, junto das equipas técnicas, de competências no domínio da avaliação, tais como a permanente recolha e sistematização da informação e a reflexão crítica sobre os processos e resultados das intervenções.

Associados a estes objectivos, são ainda identificáveis três tipos de utilidade subjacentes aos processos de avaliação de programas e intervenções, podendo assumir as seguintes nomenclaturas: uma

\footnotetext{
2 Trata-se do projecto EQUAL "Potencializar recursos, valorizar e qualificar pessoas e organizaçoes ", cuja entidade interlocutora foi a Escola Superior de Educação do Instituto Politécnico de Portalegre, no âmbito da acção 2 do Programa EQUAL (2004/EQUAL/A2/EE/141). Para além dos signatários deste texto, a equipa de avaliação externa independente integrava também uma outra investigadora: Carla Martins.
} 
utilidade instrumental: em que a avaliação é encarada como instrumento de melhoria da execução e da gestão de programas e projectos, permitindo introduzir ajustamentos ou correcções ainda no decurso dos mesmos programas e projectos; uma utilidade estratégica, no âmbito da qual a avaliação funciona como cultura de diálogo e de aprendizagem colectiva, ou seja, como prática que contribui para estimular a mobilização dos vários actores envolvidos (decisores, gestores do programa, executores, beneficiários) de modo a favorecer a consolidação de uma visão de partilha de informação estratégica e de co-responsabilização na acção; e, uma utilidade substantiva, materializada na possibilidade dos resultados da avaliação poderem sugerir a necessidade de se proceder à re-conceptualização de determinado programa ou projecto, num momento posterior, ou até à necessidade de implementar um outro programa ou projecto dirigido a outros públicos ou com outros objectivos, ultrapassando, desse modo, o papel meramente corrector identificado acima, no primeiro tipo de utilidade.

Assim identificados e caracterizados, os processos de avaliação não se resumem a meras formalidades, circunscritas a uma comparação entre as acções e os resultados previstos com as acções efectivamente realizadas e os resultados alcançados. Os processos avaliativos revelam muitas outras potencialidades, das quais se acrescentam as seguintes: permitem a reanálise das situações, o aprofundamento de diagnósticos, a reorientação e complexificação das linhas estratégicas das intervenções, a reformulação de objectivos e o alargamento e consolidação das bases de sustentação dos processos de mudança social.

Neste sentido, poder-se-á dizer que a avaliação não é um fim em si mesmo. Ela contribui, antes, para aumentar a racionalidade na tomada de decisões, na identificação de problemas, na procura de alternativas de solução, na prevenção (quando possível) de consequências e efeitos dos processos e intervenções, e, finalmente, na optimização e utilização de recursos disponíveis.

Quanto à responsabilidade e natureza dos processos avaliativos, estes podem ser de origem externa, quando há lugar à contratação de avaliadores externos às instituições e programas/projectos objecto de avaliação. Nestes casos a competência técnica e a disponibilidade das equipas de ava- liadores assumem-se como os requisitos basilares para o desenvolvimento de um trabalho de avaliação idóneo e rigoroso. Também pode haver lugar a uma auto-avaliação quando, como o próprio nome indica, os protagonistas desta coincidem com os próprios actores responsáveis pelas intervenções objecto de avaliação. Aqui a função principal do(s) avaliador(es) passa pela capacidade de envolvimento de todos os intervenientes nos processos, fomentando, paralelamente, a reflexão crítica, com o necessário distanciamento face aos processos e intervenções em que se está implicado. Finalmente, uma avaliação mista, em que, através de protocolos, os avaliadores externos são colocados em estreita articulação com as organizações que promovem as intervenções, assegurando a participação e cooperação de todos os intervenientes no processo avaliativo.

A terminar este registo, em jeito de retrospectiva e dirigido à literatura sobre o tema da avaliação, vale a pena relembrar e sistematizar os três modelos de avaliação possíveis de utilizar em função da sua temporalidade, isto é, de acordo com o momento em que esta é concretizada. Esses três modelos (ou estratégias) podem assumir as designações de: avaliação prévia ou ex-ante, a ocorrer quando determinada intervenção, projecto ou programa está prestes a ser iniciada ou já está efectivamente no seu início; a avaliação de acompanhamento ou on-going, que acompanha o percurso da intervenção, do projecto ou programa, fazendo coincidir intervenção com avaliação; e, finalmente, a avaliação sumativa ou ex-post, colocada em acção no final da intervenção, projecto ou programa, ou mesmo quando cada uma destas situações já foi concluída. Acrescente-se que cada um destes modelos ou estratégias tende a privilegiar determinados níveis de incidência no âmbito dos projectos em avaliação. Esses níveis de incidência prendem-se com as fases em que estes últimos se encontram aquando do desencadear da avaliação: concepção, operacionalização, execução e efeitos.

Foi a partir deste universo teórico-metodológico, acessível na sua generalidade a partir dos trabalhos e das propostas produzidas no campo das metodologias de avaliação, que incidiu a elaboração e implementação do dispositivo de avaliação externa independente ao projecto já aludido, o qual se apresenta a seguir, de forma sumária. 


\section{O projecto em avaliação: objectivos, território de intervenção e modelo organizativo da PD}

O projecto "Potencializar e valorizar recursos, qualificar pessoas e organizações" propôs-se instituir no território que circunscreve os municípios de Arronches, Campo Maior, Monforte e Nisa (Distrito de Portalegre) um dispositivo de formação-acção, alicerçando-se na potenciação de conexões entre estruturas da economia social e solidária (autarquias, associações de natureza variada, IPSS, escolas) com carácter intra e intermunicipais.

Neste contexto, constituiu objectivo nuclear do referido projecto a promoção de acções experimentais nos domínios do património construído, do ambiente, das artes e ofícios tradicionais e da criação de serviços de proximidade, com finalidades de formação formal e informal, visando, em última instância, promover a qualificação do mundo rural, com base numa concepção do desenvolvimento social local abrangente, participada e integrada. O dispositivo metodológico colocado em prática apresentava como objectivos específicos:

a) "Instituir no território correspondente ao de quatro municípios um dispositivo de formação/acção e em rede, envolvendo dirigentes, técnicos e profissionais;

b) Experimentar processos e práticas de animação comunitária/desenvolvimento local, em instituições tradicionalmente mais assistencialistas;

c) Centrar a formação na acção e na produção de saberes pelos formandos, valorizando, no emprego e na formação, as novas competências do trabalho social;

d) Incrementar práticas intergeracionais nos quadros institucionais de apoio, acompanhamento, inserção e protecção social dos utentes;

e) Descobrir e promover novas valias funcionais nos contextos rurais abrangidos, potenciando a sua heterogeneização" (ESEP, 2004).

$\mathrm{Na}$ génese deste projecto esteve todo um trabalho desenvolvido na acção $l$ da iniciativa comu- nitária EQUAL. O envolvimento das entidades que constituíram a parceria de desenvolvimento (PD) foi progressivo, à medida que as necessidades de implicação/actuação se evidenciavam. 0 diagnóstico de partida para este projecto não reproduziu a metodologia de trabalho habitual neste tipo de processos. Pelo contrário, a opção metodológica para a sua elaboração assentou numa especificidade que passou pela assunção de que a construção de um diagnóstico de partida para a concepção do projecto não terá sido imperativo, uma vez que já existiam estudos que apontavam claramente as necessidades desses mesmos territórios ${ }^{3}$. A elaboração do diagnóstico de partida processou-se, no essencial, recorrendo a uma metodologia de discussão de necessidades e de prioridades de intervenção a partir de uma dimensão participativa, implicando as entidades que constituíam a PD. Como princípio orientador desta opção em relação à construção do diagnóstico de partida esteve a premissa de que para problemas globais promover-se-iam soluções igualmente globais e complexas por via das potencialidades, capazes de contrariarem lógicas de intervenção segmentadas e efémeras.

O que caracterizou o modelo de organização desta PD foi, na sua essência, uma estratégia de trabalho que assentou fundamentalmente numa organização de várias actividades, animadas por cada "equipa-recurso", coexistindo com uma outra estrutura, designada por "plenários de equipas", funcionando como um fórum de reflexão partilhada entre coordenadores e técnicos das várias equipas, cuja função primordial foi a de ir estabelecendo pontes de comunicação entre as mesmas e, desse modo, garantir unidade e consistência, quer no planeamento, quer na intervenção e na realização dos produtos finais.

A parceria interna do projecto em avaliação era constituída pelas 12 entidades que se apresentam no quadro seguinte, tendo como entidade interlocutora a Escola Superior de Educação de Portalegre, integrando no seu conjunto: uma instituição de ensino superior politécnico, alguns municípios, várias IPSS, uma estrutura sindical e outras organizações da sociedade civil com preocupações específicas, inscritas no quadro de actuação do mesmo projecto.

\footnotetext{
${ }^{3}$ Na perspectiva dos coordenadores das equipas-recurso que organizaram e implementaram o projecto.

4 O projecto incluía cinco equipas-recurso, criadas e denominadas em relação ao seu objecto específico de intervenção no quadro do projecto. As equipas-rescurso eram: i) Promoção de roteiros de artesãos, ii) Dinamização de espaços museológicos e centros de interpretação do património, iii) Promoção de roteiros de educação ambiental, iv) Criação e dinamização da oficina de saberes e fazeres tradicionais, v) criação e dinamização de serviços de proximidade".
} 


\title{
Quadro n. ${ }^{\circ} 1$ - Composição da parceria interna do projecto
}

\author{
Escola Superior de Educação de Portalegre \\ Município de Arronches \\ Município de Campo Maior \\ Município de Monforte \\ Município de Nisa \\ União de Sindicatos do Norte Alentejano \\ Centro de Bem-Estar Social de Arronches \\ ICE (Instituto das Comunidades Educativas) \\ INIJovem (Associação para iniciativas para a Juventude de Nisa) \\ GEDA (Grupo de Ecologia e Desportos de Aventura) \\ Centro de Dia N. ${ }^{a}$ Sr. $^{a}$ dos Milagres \\ Voluntariado
}

Fonte: Projecto "Potencializar Recursos, Valorizar e Qualificar Pessoas e Organizações"

\section{Pressupostos, procedimentos e instru- mentos na construção de um dispositivo de avaliação: algumas notas teóricas acerca do que se pretendeu avaliar}

Na construção do modelo de avaliação externa independente, aqui reproduzido nas suas componentes mais genéricas, teve-se em conta um conjunto de preocupações de pendor teórico, metodológico e empírico ${ }^{5}$, reflectindo tanto as perspectivas teóricas mais recentes e ajustadas ao objecto em avaliação, como as propostas metodológicas disponíveis no âmbito das metodologias de avaliação, para que, em conjunto, funcionassem como matrizes de enquadramento e entendimento das dinâmicas específicas que o projecto em avaliação foi revelando ao longo da sua execução.

Neste contexto, constituiu ponto de partida uma série de indicações específicas produzidas pelo Gabinete de Gestão EQUAL, através de várias publicações, em jeito de guias de operacionalização, divulgadas e acessíveis, quer às PD no terreno, quer às próprias equipas de avaliação. Partindo da convicção de que, tanto a operacionalização do próprio projecto, como o modelo que viesse a ser produzido para a sua avaliação externa independente, ambos os processos deveriam contribuir, em última instância, para assegurar e actualizar, ao longo de todo o processo, uma gestão participada e atenta às necessidades de introdução de ajustamentos e correcções, visando a melhoria contínua da sua coerência, qualidade e eficácia. Aliás, esta convicção tornou-se sucessivamente objecto de partilha, quer pelos elementos da equipa de avaliação independente, quer pela própria $\mathrm{PD}$, à medida que esta última foi conhecendo o dispositivo metodológico, o apropriou e o interiorizou, particularmente nas suas componentes operatórias e nas respectivas finalidades.

Neste domínio em concreto, vale a pena sublinhar que constituiu factor determinante na elaboração e posterior negociação do modelo de avaliação com a PD a possibilidade desta se rever no mesmo e de, inclusivamente, lhe dirigir sugestões e correcções em termos de dimensões de análise a contemplar e de indicadores a incluir, mais específicos e relativos às características e objectivos do próprio projecto. Desta dinâmica de trabalho partilhado, entre equipa de avaliação e PD, resultou uma convergência de posições e de debate de ideias que, na prática, permitiu estabelecer um processo de interacção permanente e de apropriação de competências em matéria de avaliação. Nesta linha de procedimentos, importa frisar que foram alguns dos próprios responsáveis pelo Gabinete de Gestão EQUAL que sublinharam a necessidade da "avaliação ser para os participantes um factor de empowerment e, para os projectos, um mecanismo

\footnotetext{
${ }^{5}$ Nomeadamente a partir das considerações teóricas atrás enunciadas.
} 
de auto-regulação que visa a sua qualidade, desenvolvimento e aprofundamento contínuos", numa perspectiva "formativa e sumativa" (Figueiroa e Pimenta, 2005:15). No caso em análise, foi possível verificar estas características, desde logo na apresentação e negociação do dispositivo de avaliação independente, prolongando-se, posteriormente, ao longo de todo o processo de implementação do mesmo.

Na sequência destes pressupostos, o contexto de avaliação final para o qual se dirigiu o modelo concebido centrou-se no projecto já referenciado, tendo em conta, necessariamente, o universo dos parceiros envolvidos, as actividades e responsabilidades de que estavam incumbidos, os destinatários e os grupos-alvo das mesmas intervenções, entre outros aspectos. Recorde-se que um dos pressupostos partilhados entre a equipa de avaliação e a própria $\mathrm{PD}$, constituindo, no limite, um dos objectivos centrais do próprio processo de avaliação, foi o de contribuir para a melhoria da qualidade do projecto, tanto durante a sua execução, como na sua finalização.

Para o enriquecimento, tanto da base de partida, como do próprio percurso do processo de avaliação independente, utilizaram-se os relatórios de auto-avaliação produzidos pela equipa do próprio projecto, bem como outros documentos, igualmente elaborados no quadro da PD, de que são exemplos os Balanços de Competências (inicial e final) e o próprio diagnóstico de necessidades do território de intervenção. Paralelamente, a presença de elementos da equipa de avaliação num número significativo de reuniões das equipas-recurso e dos plenários de equipas, a par dos documentos de reflexão produzidos por estas, constituíram, analogamente, fontes de informação pertinentes para o processo de avaliação externa independente.

Dada a natureza do objecto em avaliação e de acordo com as directrizes sugeridas pelo Gabinete de Gestão EQUAL optou-se por conceber um dispositivo de avaliação de tipo on-going, isto é, uma avaliação de acompanhamento, incidindo esta, sobretudo, nas fases de operacionalização e intervenção/realização. Todavia, a equipa de avaliação independente entendeu não descurar a possibilidade de proceder igualmente a uma análise da fase de concepção do projecto, bem como da fase final do mesmo (avaliação ex-post ou sumativa), momento em que foi possível aferir, de modo particular, os efeitos e os impactes do projecto por relação aos objectivos que presidiram à sua construção.

Estas opções radicaram no pressuposto de que este tipo de avaliação surgia particularmente adaptado ao projecto em questão, já que se pretendia que o processo de avaliação funcionasse, no essencial, como um mecanismo de apoio à decisão, capaz de fornecer informação objectiva, visando uma autocorrecção permanente da intervenção, no sentido de melhorar, tanto a eficiência dos meios, como a eficácia dos resultados a atingir, não esquecendo a possibilidade de, através dela (avaliação), ir incentivando a participação dos vários parceiros envolvidos no projecto, contribuindo também, desse modo, para a consolidação da própria parceria, funcionando, à sua escala, como mais um factor de empowerment.

Incidindo assim em três fases centrais de todo o processo - operacionalização, intervenção/ /realização (avaliação on-going) e efeitos/impactes (avaliação ex-post) - e embora não dispensando a vertente da concepção do projecto por relação ao contexto de partida e ao diagnóstico subjacentes à formulação do projecto, tendo como base de referência a realidade a que este se reportava, o modelo de avaliação, cuja estrutura a seguir se pormenoriza, ganhou forma e substância a partir de uma proposta inicial que a equipa de avaliação independente apresentou à PD. Num registo eminentemente formativo, procurou-se contribuir, já nessa altura, para o cimentar de uma cultura de diálogo entre os intervenientes, com o objectivo de ajustar todos os contributos sugeridos para o enriquecimento, não só da própria avaliação do projecto, mas também para a melhor eficácia deste, no que respeita à sua concretização, em função dos meios disponíveis e dos resultados esperados.

Neste sentido, a finalidade principal do dispositivo de avaliação proposto correspondeu ao desenvolvimento e fornecimento - não só aos responsáveis pela gestão e coordenação do projecto, mas também aos demais parceiros da PD - de um conjunto de competências analíticas, reflexivas e críticas sobre o próprio processo em que os mesmos se encontravam envolvidos, contribuindo, desse modo, para a redefinição de prioridades, de decisões e de uma melhor utilização dos recursos disponíveis. Tratou-se, no fundo, de um exercício pedagógico, com funções de regulação e monitorização permanentes de todo o processo, no âmbito do qual se procurou: introduzir 
eventuais correcções e ajustamentos necessários às actividades do projecto, assegurar a sua pertinência e coerência, melhorar a sua qualidade e eficácia, favorecer a sua inovação e transferência de Recursos Técnico-pedagógicos (RTPs) e de Práticas Bem Sucedidas (PBSs), demonstrar alguns possíveis resultados e impactes e, finalmente, perspectivar desenvolvimentos futuros. Tudo isto numa lógica pautada por uma reflexão estratégica ao longo do processo de avaliação independente.

\section{Estrutura do dispositivo de avaliação: componentes, critérios, indicadores e instrumentos}

O dispositivo de avaliação elaborado e implementado gozou de uma articulação teórica e metodológica de princípios, orientações e referenciais técnico-instrumentais, de entre as várias opções metodológicas, de cunho quantitativo e qualitativo. Aliás, esta opção veio a revelar-se bastante positiva e enriquecedora, pois a partir dela foi possível aferir e articular um conjunto considerável de dados empíricos com o propósito de os examinar segundo critérios analíticos com interesse para o processo de avaliação. Na prática, acabou-se por conceber um modelo que, tanto no plano da sua sistematização teórico-conceptual, como na sua vertente de operacionalização, respeitou e concretizou uma série de orientações, emanadas e estimuladas por alguns dos responsáveis pelo acompanhamento dos processos de avaliação no âmbito do já citado Gabinete de Gestão EQUAL. Entre essas orientações, destacam-se alguns aspectos como a inovação e a combinação de metodologias e de técnicas em função das singularidades dos processos/projectos em avaliação, criando condições para entender a avaliação como "um espaço de inovação e criatividade, balizada por princípios gerais inerentes à 'qualidade' do processo, tais como: a combinação de metodologias e técnicas 'quantitativas' e 'qualitativas', que dêem conta da singularidade dos processos, dos resultados, das práticas inovadoras e dos recursos técnico-pedagógicos elaborados pelos projectos (...) e a reflexão partilhada pelos diversos actores envolvidos nas diferentes dimensões do projecto em relação directa com a 'pertinência' do seu envolvimento, em função do objecto da avaliação e da etapa da avaliação em causa" (Figueiroa e Pimenta, 2005:14-15).
Neste sentido, o dispositivo de avaliação final constituiu-se a partir de um referencial de dimensões e indicadores que, ao contrário de um modelo teórico rígido e fechado, caracterizou-se por ser, em alternativa, flexível e dinâmico, quer na sua estruturação, quer na sua implementação, tendo o mesmo sido sistematicamente afinado e aprofundado ao longo do processo de avaliação.

A necessidade de operar uma reflexão crítica, desde logo a começar pela fase da concepção do projecto, e o seu consequente prolongamento nas fases do projecto identificadas atrás - operacionalização, realização/execução e efeitos/impactes - conduziu a equipa de avaliação para a apresentação de uma proposta de modelo de avaliação, não na forma de um documento acabado, mas sim como uma base de trabalho, a aprofundar do decurso do processo de avaliação, contando com os contributos e sugestões da PD ou dos responsáveis pelas actividades inscritas no projecto. Desde o exercício inicial de elaboração do modelo, até ao desenho final do mesmo e à elaboração dos instrumentos de recolha de informação junto da PD, partiu-se de uma lista de dimensões/componentes para a correspondente enumeração de indicadores (quantitativos e qualitativos). Paralelamente a este exercício analítico, procedeu-se à correspondência destas mesmas dimensões e respectivos indicadores a um conjunto de critérios avaliativos, entendidos como pontos de chegada sobre os quais se procurou produzir informação útil para o projecto. Subjacente a este procedimento esteve a tentativa de materializar um dos objectivos centrais deste modelo de avaliação, o qual, aliás, se encontra reproduzido noutros modelos congéneres: a reunião de informação necessária que facilitasse, de forma rigorosa e coerente, a compreensão do projecto (objecto de avaliação) nas suas várias fases, vertentes e dinâmicas.

Constituindo uma avaliação de acompanhamento, visando a incorporação dos respectivos resultados na decurso do próprio processo, na base de uma postura formativa e de cunho pedagógico, fornecendo pistas úteis para a melhoria da performance da intervenção e qualidade de desempenho da PD, foi assumido pela equipa de avaliação a necessidade de todo o processo avaliativo decorrer em simultâneo com as próprias actividades, tendo sido avançado como condição base de trabalho a garantia da disponibilização de toda a informação solicitada pela equipa. 
No que se refere aos instrumentos e técnicas de recolha de informação, sistematização e análise da informação empírica e tratando-se de um processo de avaliação que pressupôs, tanto quanto possível, um acompanhamento permanente das acções no terreno, a investigação-acção foi assumida como a melhor estratégia metodológica de suporte ao desenvolvimento do trabalho. No âmbito desta investigação-acção, couberam objectivos de investigação (pesquisa de informação susceptível de ser analisada segundo pressupostos teóricos e metodológicos de pendor científico), bem como objectivos de acção/intervenção, já que, o dispositivo de avaliação proposto e concretizado foi transversal ao processo de planeamento e à realização das acções subjacentes ao projecto.

Nesta perspectiva, pretendeu-se tornar o processo de avaliação, desde o seu início, num instrumento de apoio, não só para proceder a balanços parciais a respeito da intervenção concretizada, mas também para ajudar a orientar a intervenção de forma mais informada, visando uma maior eficiência no que respeita à utilização dos meios envolvidos e uma maior eficácia na concretização dos objectivos do projecto.

Assim, quer para a aferição das componentes/dimensões de análise e dos indicadores que deram forma ao dispositivo de avaliação, quer para a análise e sistematização dos dados relativos a todo o processo, recorreu-se a várias técnicas de recolha de informação, numa perspectiva articulada e combinada, designadamente: a pesquisa bibliográfica, a análise documental, a entrevista a responsáveis pelas actividades no âmbito do projecto (na primeira fase) e aos destinatários do projecto (na segunda fase), o inquérito por questionário ${ }^{6}$ e a elaboração de grelhas de análise orientadas para o registo e sistematização dos conteúdos e das dinâmicas das reuniões, quer das equipas-recurso, quer dos plenários de equipas.

Muitas das dimensões e indicadores seleccionados retomaram propositadamente algumas questões que deram corpo aos relatórios de autoavaliação, produzidos pela própria PD. O objectivo foi, no essencial, procurar a articulação entre os dois procedimentos de avaliação, sugerida inclusivamente, e mais uma vez, pelo próprio Gabinete de Gestão EQUAL.

Seguem-se, de acordo com uma perspectiva simplificada, as dimensões/componentes, os indicadores, os critérios e os instrumentos de recolha de informação idealizados para o processo de avaliação externa independente. As dimensões/componentes traduzem as fases do processo avaliativo, enquanto os assuntos/tópicos simbolizam os indicadores explorados no âmbito do processo de recolha de informação empírica. Os indicadores constituem as questões em concreto (constantes, por exemplo, nos inquéritos por questionário e nos guiões de entrevista), patentes nos vários instrumentos de recolha de informação implementados. Finalmente, os critérios correspondem aos elementos analíticos que foram aferidos na sequência das dimensões e dos indicadores seleccionados.

${ }^{6}$ Aplicado junto da PD nos meses de Janeiro e Fevereiro de 2007 (fase 1) e nos meses de Julho e Agosto do mesmo ano (fase 2). 


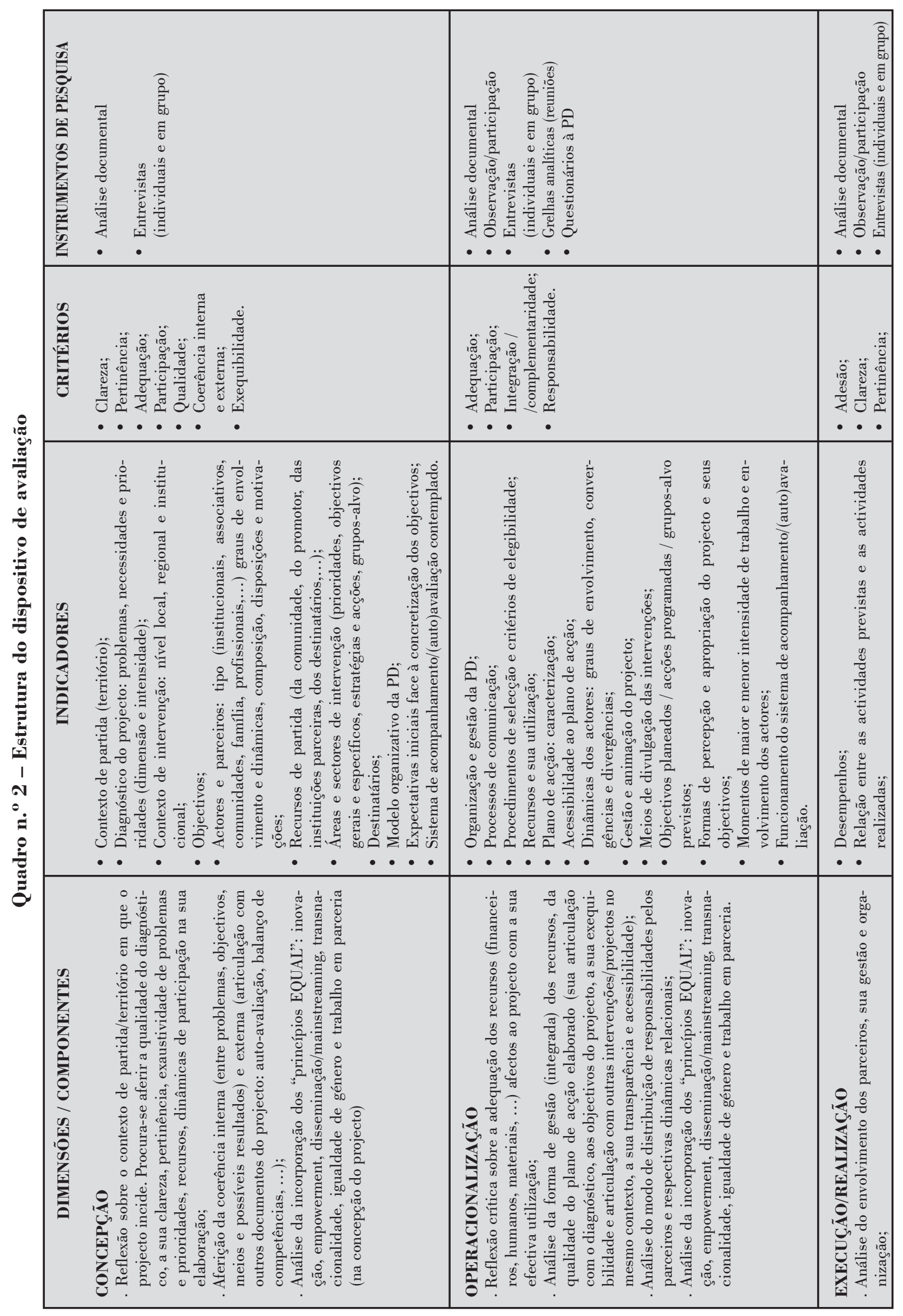




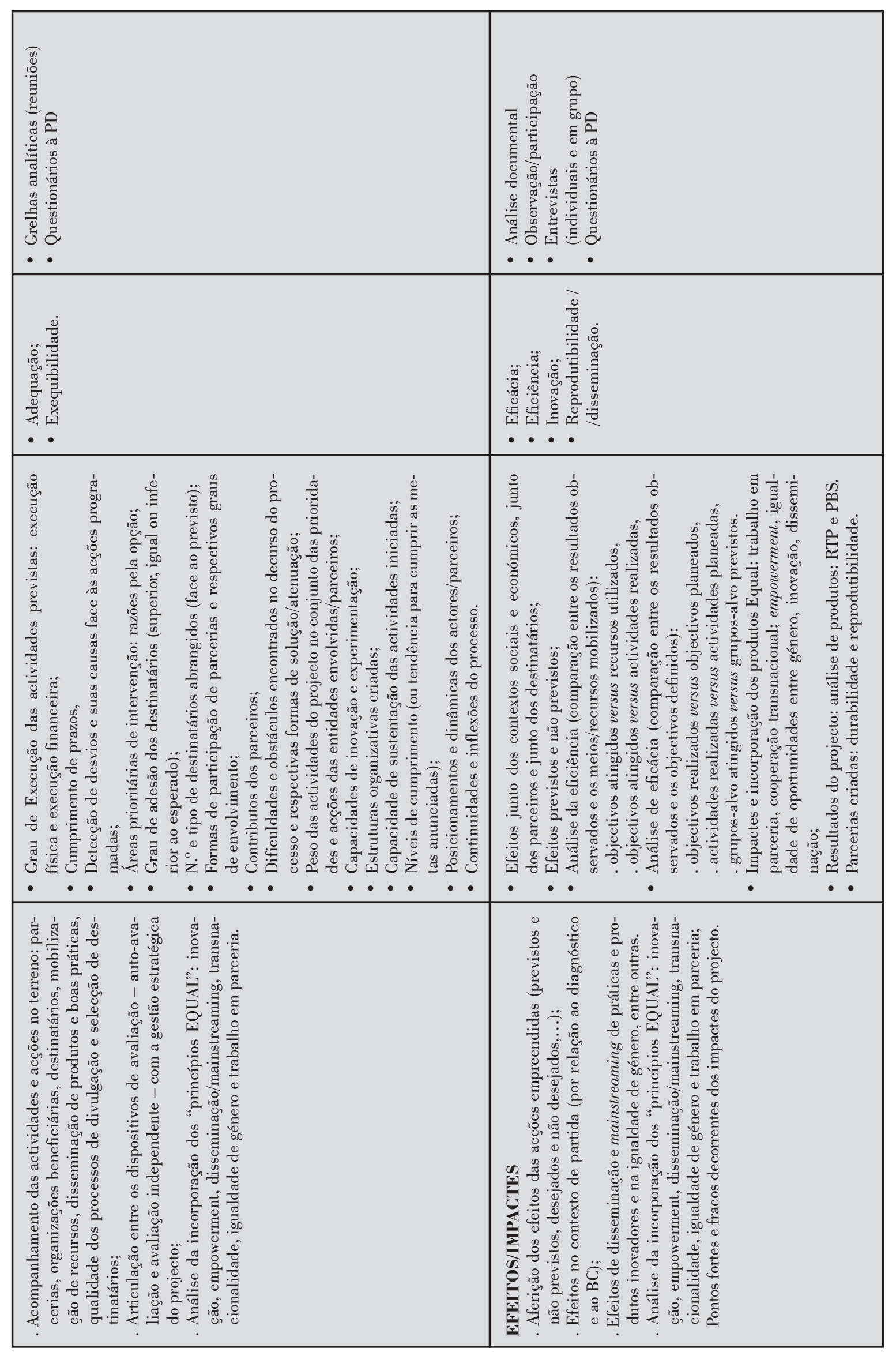




\section{Análise diacrónica e sectorial do projecto: uma componente de avaliação de índole qualitativa}

Em qualquer processo de desenvolvimento social, em projectos de grande ou reduzida dimensão, mas todos eles com vários actores sociais em presença, coexistem normalmente diferentes entendimentos e modelos, quer na discussão das melhores soluções para determinados problemas ou prioridades, quer na respectiva implementação e concretização de acções e medidas. Paralelamente, é frequente encontrar no curso desses processos de desenvolvimento, ritmos, calendários e momentos de particular avanço, alternados com fases de menor intensidade dos trabalhos, o que pode ser explicado, ora com base na assunção de que determinados assuntos/problemas merecem uma reflexão continuada em busca do desejado aprofundamento, ora por inércias, de diferente natureza, cujas implicações se podem repercutir de forma negativa no desenvolvimento dos mesmos processos.

Este tipo de leitura tem interesse num processo avaliativo como aquele sobre o qual se tem vindo a discorrer, já que se privilegiou no dispositivo de avaliação construído uma dimensão sócio-relacional e de avaliação das respectivas dinâmicas de discussão e dos posicionamentos dos actores implicados face aos temas em análise no âmbito do próprio projecto. Nesta perspectiva, considerou-se que a integração de uma componente de registo e análise de informação de cariz qualitativo no dispositivo de avaliação complementaria e reforçaria o estudo articulado de variáveis e indicadores quantitativos, com utilidade e pertinência para os objectivos de um sistema de avaliação que se pretendia formativo, participado e simultâneo ao próprio projecto em avaliação.

A forma de captar e registar esses elementos empíricos materializou-se com recurso a um dispositivo metodológico assente essencialmente no acompanhamento dos trabalhos e das etapas do projecto, de forma incisiva e pormenorizada. No fundo, tratou-se de uma monitorização, concretizada mediante um mecanismo de observação e participação, por parte de elementos da equipa de avaliação, em várias reuniões de trabalho, não só das equipas-recurso do projecto, mas também dos plenários de equipas.
Qual a utilidade deste tipo de informação para o próprio projecto em avaliação e, especificamente, para a Parceria de Desenvolvimento? Tanto do ponto de vista teórico, como num registo mais pragmático, considerou-se que a informação recolhida e analisada por via desta estratégia metodológica podia revelar-se útil à própria $\mathrm{PD}$, já que esta tomaria consciência da forma como as suas dinâmicas de trabalho, designadamente os avanços e/ou recuos por ela protagonizados, poderiam influenciar o desenvolvimento do próprio projecto. Confrontar a PD com os momentos e as fases de trabalho mais significativos, mas também com o seu inverso, retirando daí as ilações necessárias para a auto-reflexão no seio da própria PD acerca do processo de implementação do projecto, poderia contribuir, afinal, para a materialização de dois dos principais objectivos de qualquer processo de avaliação: o de possibilitar uma permanente sistematização da informação e reflexão crítica sobre os processos e resultados das intervenções nas quais se estava envolvido, por um lado; e o de impulsionar uma cultura de diálogo e de aprendizagem colectiva que estimulasse a mobilização dos vários actores envolvidos (coordenadores de acções, técnicos e destinatários), de modo a favorecer a consolidação de uma visão de partilha de informação estratégica e de co-responsabilização na acção, por outro.

Este tipo de avaliação, a qual se pretendeu que fosse apropriada e discutida no seio da PD, apoiou-se na elaboração de vários instrumentos analíticos, entre os quais, uma cronologia geral do projecto, dando forma e substância a uma componente deste exercício de avaliação que poderemos designar por memória do processo. Por outro lado, esta análise/avaliação, de cariz essencialmente qualitativo e suportado por uma estratégia metodológica de tipo intensivo-qualitativa, prolongou-se recorrendo a uma sistematização e respectiva análise de um vasto conjunto de material empírico, reunido e organizado na sequência do acompanhamento e participação em variadíssimas sessões de trabalho/reuniões, quer no âmbito dos plenários de equipas, quer por via de várias reuniões sectoriais levadas a cabo pelas equipas-recurso.

No cerne da análise/avaliação, centrada no acompanhamento destas reuniões de trabalho realizadas pela $\mathrm{PD}$, esteve a preocupação de sistematizar conteúdos e dinâmicas aí decorrentes, com relevância objectiva para o processo (leia-se im- 
plementação do projecto). Registe-se, porém, uma pequena dificuldade: a de reconstituir uma memória efectivamente global do projecto e de todas as suas especificidades, já que nem sempre a informação cordialmente disponibilizada pelas equipas-recurso reunia elementos suficientes que permitissem avançar para uma avaliação suficientemente substantiva e objectiva, tratando-se de documentos (geralmente na forma de actas de reuniões) muito sucintos na sua essência. Independentemente desta pequena limitação - minorada pela informação recolhida sobretudo nas reuniões em que participou um elemento da equipa de avaliação externa independente - é, contudo, possível avançar algumas leituras cujo interesse principal dirige-se, precisamente, para uma visão global acerca das dinâmicas sócio-relacionais, dos conteúdos em discussão, das acções concretizadas e a concretizar e, finalmente, das próprias representações sociais dos elementos da PD acerca do seu próprio trabalho e respectiva evolução.

\section{a) Cronologia geral do projecto}

Com este instrumento de avaliação procurou-se proporcionar uma visão sequencial e cronológica da evolução do projecto em avaliação, numa perspectiva diacrónica. Em concreto, pretendeu-se reunir, numa imagem global do processo, uma série de factos, acontecimentos, acções, finalidades e meios associados ao projecto em avaliação. Ofereceu-se, assim, a possibilidade de identificar momentos-chave, fases de aprofundamento ou de relativa estagnação no desenvolvimento dos trabalhos, mudança de ritmos e de conteúdos, realização de reuniões com interesse para o projecto, inflexões de orientação decisivas, entre outros aspectos, constituindo, no conjunto, a memória do processo.

O objectivo último do tipo de informação, de índole qualitativa, proporcionada por este instrumento de avaliação, consubstanciou-se no contributo para a criação de uma base de informação sistematizada e acumulável sobre o processo em avaliação, tendo-se procurado, analogamente, contribuir para uma aprendizagem conjunta e um ajustamento recíproco de actores sociais implicados, recolocando-os assim noutro patamar de compreensão e interacção, na perspectiva de que os mesmos pudessem melhorar as suas decisões e acções a executar futuramente ${ }^{7}$.

A cronologia seguinte reúne, numa perspectiva genérica e transversal, um conjunto de indicações que traduziram a evolução do projecto avaliado, destacando alguns dos seus principais momentos, etapas e iniciativas. Como qualquer cronologia, também esta é susceptível de ter omitido determinadas referências ou, pelo contrário, de ter registado elementos que foram diferentemente considerados de maior ou menor relevância para a compreensão do processo por parte dos parceiros envolvidos na PD. Todavia, o objectivo da mesma manteve-se, o qual remetia para a possibilidade de facultar uma sistematização, com utilidade para os elementos da PD, visando, em última instância, proporcionar-lhes uma imagem sequencial e temática do conjunto das reflexões e iniciativas que materializaram o projecto no âmbito do qual eram protagonistas.

\footnotetext{
Esta metodologia pode ser encontrada em literatura específica sobre processos de avaliação, tendo, no caso concreto da cronologia, sido já testada em trabalhos publicados anteriormente (COSTA, António Firmino, e ALVES, João Emílio, 1996).
} 
Quadro no 3 - Cronologia geral do projecto

\begin{tabular}{|c|c|}
\hline Data & Momentos/etapas/iniciativas \\
\hline Setembro/2005 & . Início do projecto \\
\hline Novembro/2005 & . Plenário de Equipas \\
\hline Novembro/2005 & $\begin{array}{l}\text { Transmissão de informações relativas ao arranque do projecto, quer do ponto de vista técnico- } \\
\text {-pedagógico, quer do ponto de vista financeiro }\end{array}$ \\
\hline Dezembro/2005 & . Realização do $1 .^{\circ}$ exercício de auto-avaliação \\
\hline Janeiro/2006 & . Levantamento dos recursos ambientais a incluir nos percursos pedestres (trabalho de campo) \\
\hline Janeiro/2006 & . Relatório de Balanço de Competências inicial \\
\hline Março/2006 & . Levantamento dos recursos ambientais a incluir nos percursos pedestres (trabalho de campo) \\
\hline Abril/2006 & $\begin{array}{l}\text { - Aplicação de inquéritos na localidade de Ouguela e preparação do percurso pedestre da Cen- } \\
\text { tral da Velada (trabalho de campo) }\end{array}$ \\
\hline Abril/2006 & . Plenário de Equipas \\
\hline Junho/2006 & . Plenário de Equipas \\
\hline Junho/2006 & $\begin{array}{l}\text { - Criação Oficina de Saberes e Fazeres Tradicionais no Centro de Dia N. }{ }^{\text {a }} \text { Sr. }^{\text {a }} \text { dos Milagres } \\
\text { - Assumar }\end{array}$ \\
\hline Julho/2006 & . Plenário de Equipas \\
\hline Julho/2006 & . Percurso pedestre à Central da Velada \\
\hline Agosto/2006 & . Aplicação do guião reformulado num encontro de crianças no Centro Ambiental de Ouguela \\
\hline Setembro/2006 & . Plenário de Equipas \\
\hline Setembro/2006 & $\begin{array}{l}\text { - Apresentação da proposta de avaliação externa independente pelo Departamento de Ciências } \\
\text { Sociais e Humanas da Escola Superior de Educação de Portalegre (ESEP) }\end{array}$ \\
\hline Setembro/2006 & . Plenário de Equipas \\
\hline Outubro/2006 & . Realização, em Madrid, de um encontro transnacional \\
\hline Outubro/2006 & . Plenário de Equipas \\
\hline Novembro/2006 & . Plenário de Equipas \\
\hline Dezembro/2006 & . Realização do $2 .^{\circ}$ exercício de auto-avaliação \\
\hline Janeiro/2007 & $\begin{array}{l}\text { Reunião da rede temática realizada em Lisboa, onde foram caracterizados os produtos, bem } \\
\text { como a definição do seu carácter inovador }\end{array}$ \\
\hline Janeiro/2007 & . Plenário de Equipas \\
\hline Fevereiro/2007 & $\begin{array}{l}\text { - Apresentação do memorando sobre o recurso técnico-pedagógico, no Centro Ismaili, em Lis- } \\
\text { boa }\end{array}$ \\
\hline Fevereiro/2007 & $\begin{array}{l}\text { Realização de deslocações ao campo para recolha de informações sobre os diferentes tipos } \\
\text { de culturas, posteriormente analisadas em contexto sala de aula (Produtos da Terra - Campo } \\
\text { Maior) }\end{array}$ \\
\hline Fevereiro/2007 & . Plenário de Equipas \\
\hline Fevereiro/2007 & . Encontro transnacional em Metz, com participação de representantes da PD \\
\hline Março/2007 & $\begin{array}{l}\text { Apresentação, em plenário de equipas, de um bago de um produto em cacho processo me- } \\
\text { todológico do Roteiro dos Fontanários de Campo Maior, como modelo para outros bagos de } \\
\text { produtos }\end{array}$ \\
\hline Março/2007 & $\begin{array}{l}\text {. Criação da Oficina de Saberes e Fazeres Tradicionais no Centro de Bem-estar Social de Ar- } \\
\text { ronches }\end{array}$ \\
\hline Março/2007 & $\begin{array}{l}\text { Realização de encontro transnacional, em Portalegre, dedicado ao tema "certificação de pro- } \\
\text { dutos regionais"; }\end{array}$ \\
\hline & . Realização de um seminário transnacional subordinado ao tema "funcionamento em rede" \\
\hline Março/2007 & . Plenário de Equipas \\
\hline Abril/2007 & - Realização da actividade: deslocação ao campo com os alunos envolvidos na organização da \\
\hline Abril/2007 & actividade: levantamento cartográfico do local (Chão da Velha), em Nisa \\
\hline & . Apresentação do relatório intercalar de avaliação externa independente \\
\hline Maio/2007 & . Actividade "Conto da história de Botoa", no centro comunitário de Campo Maior \\
\hline Maio/2007 & . Percurso pedestre em Chão da Velha, com um guia local \\
\hline Maio/2007 & . Sessão de Contadores de Histórias \\
\hline Junho/2007 & . Apresentação no Cine-Teatro de Nisa de todo o trabalho desenvolvido pelas equipas-recurso \\
\hline Julho/2007 & "Roteiro de Artesãos e Espaços Museológicos" \\
\hline Julho/2007 & . Seminário de divulgação do projecto à ESEP: Balanço institucional e apresentação de produtos \\
\hline Julho/2007 & . Plenário de Equipas \\
\hline Julho/2007 & . Validação final dos produtos, em Lisboa \\
\hline Setembro/2007 & . Plenário de Equipas \\
\hline Outubro/2007 & . Plenário de Equipas \\
\hline Novembro/2007 & . Realização do exercício de auto-avaliação final \\
\hline Novembro/2007 & . Relatório de Balanço de Competências final \\
\hline Dezembro/2007 & . Apresentação de resultados do relatório final de avaliação externa independente \\
\hline
\end{tabular}

Fonte: Relatório final do processo de avaliação externa independente do projecto EQUAL "Potencializar recursos, valorizar e qualificar pessoas e organizações". 


\section{b) Análise sectorial do projecto: plenários de equipas e equipas-recurso - conteúdos e dinâmicas}

Na sequência do atrás descrito a respeito da cronologia construída para a memória do processo, também as dinâmicas e os conteúdos debatidos e registados ao longo das várias reuniões, quer dos plenários de equipas, quer das equipas-recurso, mereceram uma apreciação de índole qualitativa. Para tal, foi criada uma matriz de registo de informação - Matriz Actores x Intervenções (MAI) ${ }^{8}$ - teoricamente orientada por princípios de cariz avaliativo, e pragmaticamente preenchida a partir, ora das anotações do elemento da equipa de avaliação destacado para a observação e acompanhamento dos trabalhos de forma permanente, ora a partir das próprias sínteses elaboradas e remetidas pela coordenação do projecto em avaliação (quadro n. ${ }^{\circ} 4$ ).

No preenchimento desta matriz, teve-se particularmente em conta os problemas/necessidades sucessivamente levantados ao longo do processo, as respectivas propostas de solução e sugestões avançadas em ordem aos problemas enumerados, as manifestações de apoio/convergências entre os actores sociais implicados, as posições divergentes, e, por fim, alguns comentários e expectativas relevantes para a compreensão do processo, designadamente ao nível da sua dimensão sócio-relacional.

O quadro n. ${ }^{\circ} 4$ constitui o ponto de chegada dos conteúdos debatidos e das dinâmicas observadas no âmbito das reuniões de plenários de equipas, dando particular atenção ao levantamento de problemas inerentes ao projecto e às respectivas propostas de solução/sugestões. $\mathrm{O}$ horizonte temporal abrangido por esta metodologia, no âmbito da qual se produziu a respectiva grelha analítica, decorreu entre Novembro de 2005 e Outubro de 2007. A partir deste instrumento analítico, bem como da anterior cronologia, foi possível acompanhar o projecto, monitorizando-o e proporcionando à respectiva $\mathrm{PD}$, em vários momentos, algumas leituras e elementos informativos com utilidade, não só para os respectivos exercícios de auto-avaliação, mas também para todo o trabalho que ia sendo organizado no âmbito da implementação do projecto.
Nestas reuniões discutiram-se várias temáticas, com particular ênfase em questões relacionadas, numa primeira fase, com a implementação e funcionamento das equipas-recurso, procurando integrar na sua constituição elementos de várias instituições parceiras com afinidades de trabalho em determinados temas. Com a continuidade dos plenários, é claramente observável uma dinâmica evolutiva de conteúdos debatidos, centrada em temas diferentes. Aliás, o que ressalta à primeira vista, mediante um olhar mais qualitativo ao conjunto das reuniões analisadas, prende-se com a detecção de uma mudança/evolução de conteúdos segundo uma lógica que acompanha a concretização de etapas do próprio projecto.

Se à primeira vista tal constatação pode não constituir surpresa, o que a torna particularmente importante do ponto de vista da avaliação é o facto de, por exemplo, se atendermos aos sucessivos problemas/questões levantadas pela $\mathrm{PD}$, verificar-se que esses problemas, relativos ao ano de 2006, vão sendo substituídos por outros, evidenciando uma passagem do debate centrado em questões relacionadas, numa primeira fase, com aspectos inerentes à montagem e implementação do modelo de organização da própria parceria, para, numa segunda fase, o debate centrar-se nas dificuldades decorrentes da mobilização dos destinatários das acções a empreender no âmbito do projecto. Depois, os problemas discutidos passaram a relacionar-se com as próprias acções em concreto, seguindo-se uma particular preocupação dirigida aos recursos humanos necessários, voltando novamente, em reuniões seguintes, a centrarem-se as preocupações nas dificuldades relacionadas com a implementação de determinadas acções (particularmente os atrasos verificados na respectiva execução) para, finalmente, nas últimas reuniões analisadas, o enfoque voltar a dirigir-se para os destinatários e mais uma vez para as acções a empreender.

Já no curso do ano de 2007, voltaram a ser as questões de ordem organizativa a assumir maior relevância no âmbito das discussões dos plenários de equipas, embora dirigidas nesta fase para aspectos relacionados com as etapas finais do projecto, 


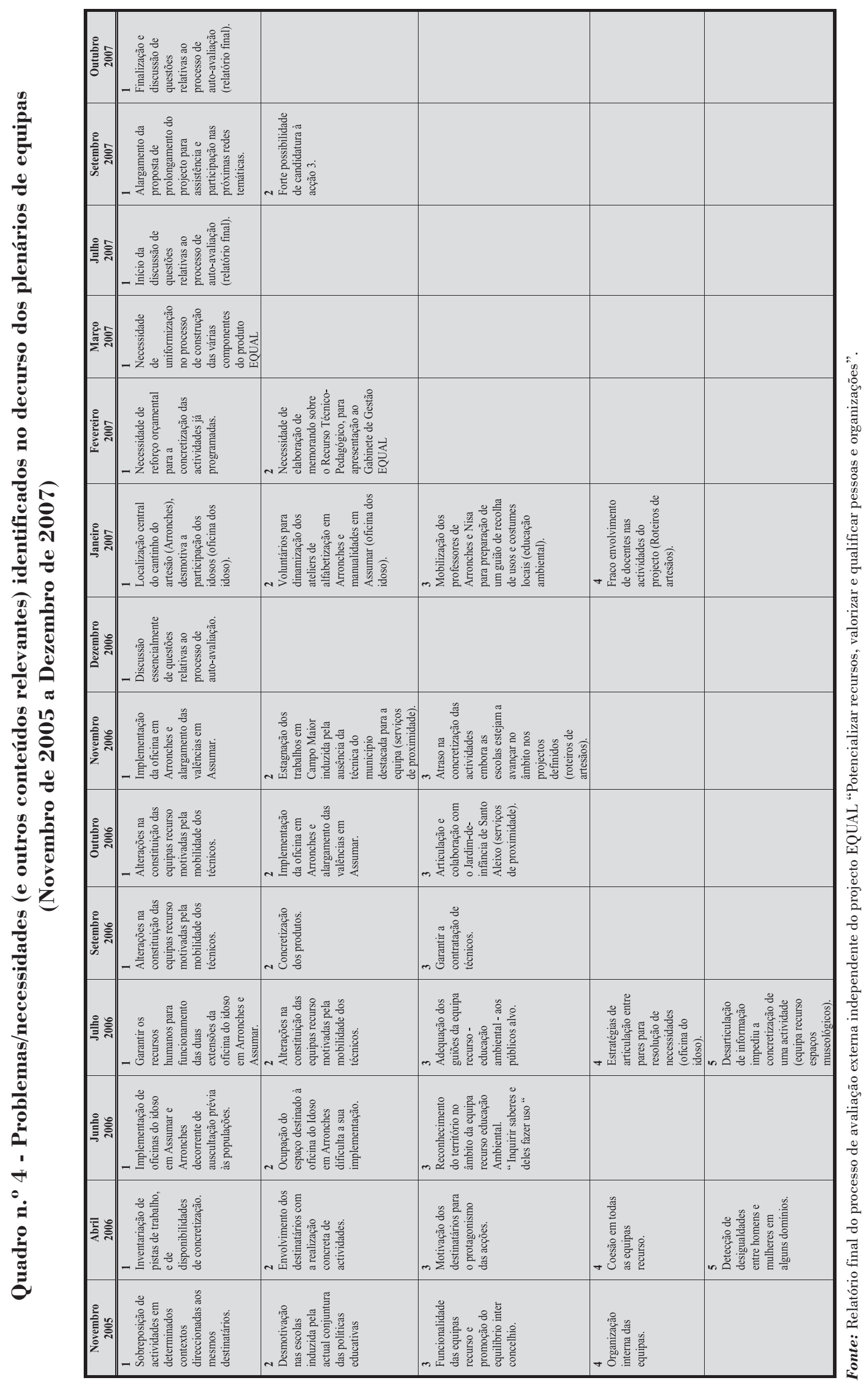


designadamente a elaboração e discussão do produto EQUAL a propor. Paralelamente, ganha espaço de debate no seio da PD a preparação e discussão partilhada do processo de auto-avaliação final, ao mesmo tempo que são divulgadas informações úteis para o trabalho da PD no que respeita à sua participação noutras reuniões temáticas e de validação de produtos, relativas a outras PD inerentes a outros projectos EQUAL.

Muito embora esta lógica evolutiva de conteúdos pareça, à primeira vista, coerente e demonstrativa de que a evolução dos problemas discutidos traduz uma normal e esperada evolução do próprio projecto (do modelo organizativo e das equipas-recurso, parte-se para a mobilização de destinatários, de acções, de recursos; depois para a programação das novas acções, para a identificação dos destinatários, de outras acções e dos produtos finais); importa ressalvar que, pelo meio, também é observável, numa ou noutra reunião, o reequacionamento da constituição da própria $\mathrm{PD}$, não por inoperância desta, mas sim pela necessidade de substituição de técnicos, destacados pelas instituições parceiras. Tal situação, apesar de não ter posto em causa a sequência das etapas inerentes à implementação do projecto, proporcionou algumas, embora pequenas, perturbações no funcionamento das próprias equipas-recurso, sendo notória a referência a esta situação pelo menos em três plenários de equipas (de Julho a Outubro de 2006).

Por outro lado, a análise qualitativa decorrente desta matriz permitiu observar que muitos dos problemas/questões enunciados ao longo dos vários plenários de equipas convergiram, na sua essência e generalidade, para os problemas/questões igualmente apontados pelos técnicos da PD, através dos inquéritos por questionário aplicados em duas fases (intercalar e final) no âmbito da avaliação externa independente. Tal constatação permitiu avançar, com relativa propriedade, a coerência demonstrada, tanto ao nível das metodologias implementadas no âmbito deste processo de avaliação, combinando técnicas e instrumentos de índole quantitativa e qualitativa, como ao nível dos próprios conteúdos e das respostas dos inquiridos, já que a convergência de temas, designadamente a identificação dos problemas, foi claramente evidente.
Paralelamente à enunciação dos problemas com maior visibilidade reconhecidos pela $\mathrm{PD}$, foi possível, por via deste procedimento analítico, enumerar um conjunto de sugestões e propostas de solução avançadas em sede de plenários de equipas. Sem prejuízo da diversidade dessas sugestões/propostas de solução, verificável mediante uma análise mais fina ao longo do processo de avaliação e dirigida a todas as reuniões de plenários de equipas, compreendidas no mesmo período atrás enunciado, constatou-se, mais ou menos repetidamente, dois grupos de soluções: um primeiro direccionado para a questão/problema dos recursos humanos necessários à implementação das acções no terreno, sobretudo no primeiro conjunto de reuniões analisadas; e um segundo grupo orientado para sugestões relacionadas com a mobilização de destinatários das acções, estas últimas identificáveis, com maior incidência, nas últimas reuniões de plenários de equipas. As restantes propostas de solução relacionaram-se com problemas mais específicos, enquadráveis em algumas das equipas-recurso, com maior visibilidade já na fase final, tendo sido sugeridas estratégias de trabalho, no interior das mesmas, tendentes à elaboração e montagem das várias componentes do produto EQUAL a propor aquando da finalização do projecto.

\section{Modos de incorporação dos princípios EQUAL: proposta de operacionalização do princípio "Igualdade de Género" para efeitos de avaliação}

Um dos pressupostos base inerentes ao Programa EQUAL passava por englobar um conjunto de princípios que deveriam nortear a gestão e o desenvolvimento, quer do programa, quer dos projectos abrangidos por este, devendo os mesmos princípios serem estruturantes das intervenções protagonizadas pelas respectivas PD.

Assim e no âmbito do dispositivo de avaliação que temos vindo a expor, pretendeu-se dar uma especial ênfase a esta dimensão do processo, a partir inclusivamente de um conjunto de indicadores propostos pelo Gabinete de Gestão EQUAL. Para todos os princípios - inovação, empowerment, disseminação/mainstreaming, transnacionalidade, igualdade de género e trabalho em parceria - foram criados indicadores com o propósito de captar e de 
medir o grau de apropriação revelado pela PD a respeito dos mesmos. Neste sentido, procurou-se aprofundar a generalidade dos mesmos princípios do ponto de vista da sua apropriação, recorrendo a vários outros indicadores para além das sugestões de operacionalização sugeridas na documentação disponibilizada pelo Gabinete de Gestão EQUAL.

A título de ilustração, escolheu-se reproduzir e apresentar, no quadro deste texto, o esquema analítico que presidiu a construção de um conjunto de indicadores relativamente ao princípio igualdade de género (IG). O modelo teórico construído para analisar a questão da integração deste princípio na $\mathrm{PD}$, no âmbito do processo de avaliação externa independente, articulou-se em torno de três dimensões analíticas. Esta estrutura tripartida procurou remeter o trabalho de análise para diferentes expressões da IG, identificáveis no decurso do trabalho da PD.

A primeira dimensão deste modelo designa-se de "expressão objectiva" da IG, na medida em que remete para diferentes produções materiais, quantitativamente mensuráveis, relacionadas com a IG no seio da PD. Esta dimensão organiza-se em duas componentes principais, uma delas referente ao funcionamento/execução da PD na sua articulação com a IG e outra relacionada com a integração da IG nos impactes da intervenção da PD, componentes sobre as quais recaiu o trabalho de observação em função de indicadores EQUAL.

A segunda dimensão do modelo remete para dimensões mais subjectivas e intersubjectivas da integração da IG na PD. Assim, esta dimensão corresponde àquela através da qual se pretendeu estudar as formas de percepção, avaliação e satisfação da generalidade dos técnicos envolvidos no projecto com a integração da IG na PD. Organizou-se, igualmente, em torno de duas componentes: por um lado, a percepção (inter)subjectiva dos intervenientes na PD sobre o nível de integração da IG na PD, a qual se consubstancia analiticamente num indicador de percepção avaliativa; e por outro, a satisfação com o nível percebido de integração da IG na $\mathrm{PD}$, que se detalha num indicador de nível de satisfação acerca de alguns pontos centrais da integração da IG na PD. Com este desdobrar, procurou-se separar aquilo que é a percepção de um determinado objecto de debate e trabalho entre parceiros, o qual configura um princípio EQUAL, daquilo que é o nível de satisfação com a integração desse mesmo objecto no seio do trabalho em parceria.

Finalmente, a terceira dimensão do modelo denomina-se "expressão operatória" da IG e reporta-se ao desenvolvimento de acções específicas acerca da IG no quadro dos trabalhos desenvolvidos. Esta dimensão tem uma única componente, relativa ao desenvolvimento de acções específicas sobre a IG no trabalho desenvolvido pela PD.

$\mathrm{Na}$ prática, os indicadores construídos para darem conta destas dimensões centrais do estudo de avaliação das formas de integração da temática da IG na PD estão estruturados, como referido acima, em função de duas componentes de base. Uma primeira componente, dedicada à percepção avaliativa desta temática e uma segunda componente, que tenta discriminar alguns aspectos centrais dos níveis de satisfação dos técnicos inquiridos face à integração da Igualdade de Género na Parceria de Desenvolvimento. Ora, estas duas componentes, são, por sua vez, atravessadas por três eixos centrais, em função dos quais gravitam elementos considerados relevantes do trabalho em parceria desenvolvido no quadro da Parceria de Desenvolvimento: o funcionamento da parceria de desenvolvimento, os seus produtos e os seus impactes (figura 1).

Assim, em jeito de síntese, diríamos que o que se procurou estudar através deste modelo analítico foi a percepção, avaliação e níveis de satisfação dos respondentes quanto à integração da Igualdade de Género no funcionamento, nos produtos e nos impactes do trabalho desenvolvido pela Parceria de Desenvolvimento, relativa ao projecto em avaliação. Desta maneira, os indicadores construídos e traduzidos em questões nos instrumentos de pesquisa posteriormente utilizados, designadamente o inquérito por questionário (aplicado em dois momentos distintos durante a implementação do projecto) surgem em função do espaço definido pelos constrangimentos cruzados daquelas determinações analíticas. Os resultados alcançados permitiram uma melhor compreensão e avaliação do real grau de apropriação deste princípio EQUAL pela PD e pelo projecto em causa, paralelamente a outras informações e dados objectivos, resultantes da globalidade do processo de avaliação, traduzidas em conclusões e recomendações estratégicas. 
Figura 1 - Modelo de análise da integração da IG na PD

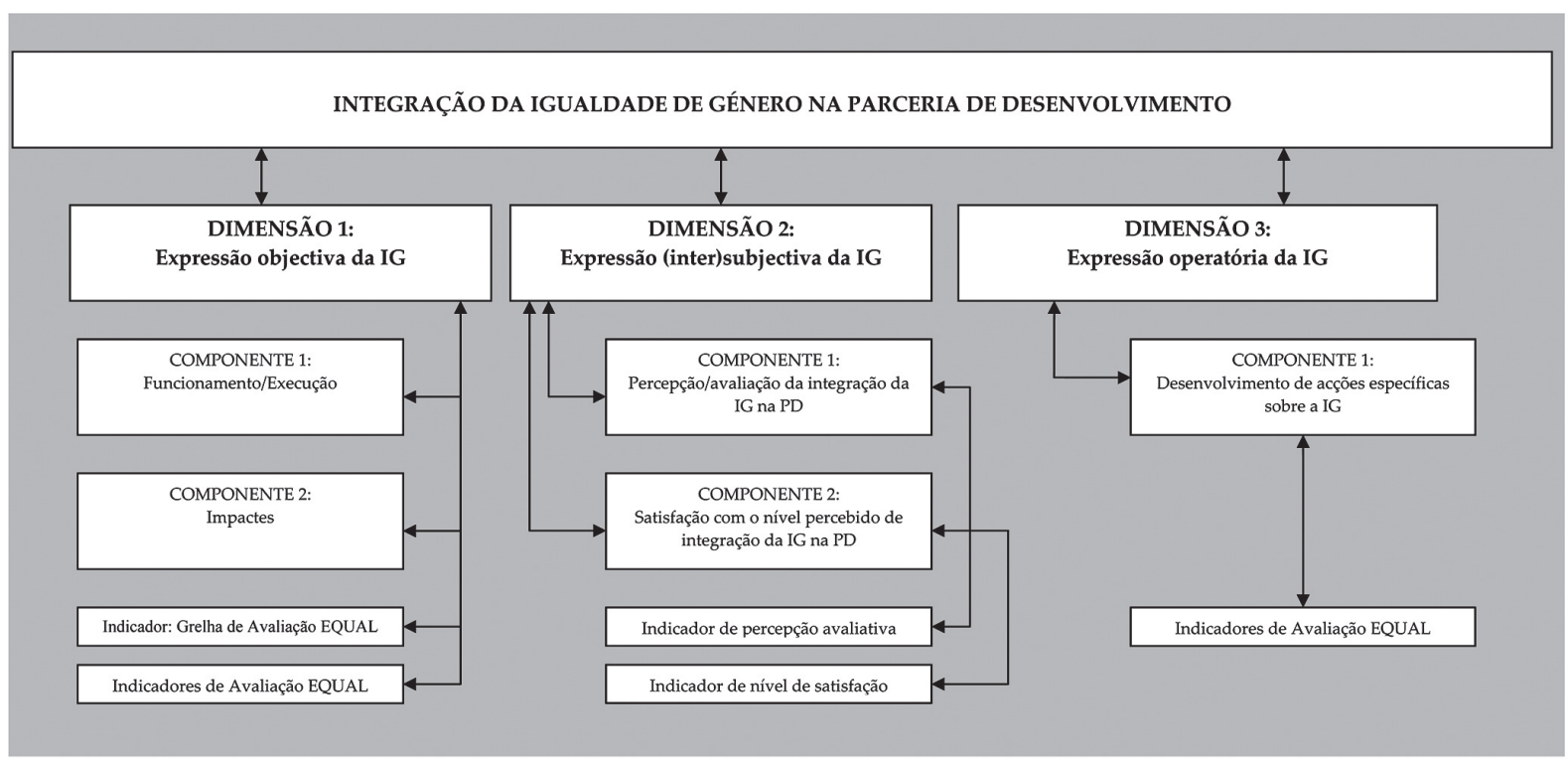

Fonte: Relatório final do processo de avaliação externa independente do projecto EQUAL "Potencializar recursos, valorizar e qualificar pessoas e organizações".

\section{Bibliografia}

ALVES, João Emílio, MARTINS, Alexandre Cotovio e CHETA, Rita, 2007, Emprego, Formação e Redes Sociais. Processos, Dinâmicas e Impactes, Lisboa, Celta Editora.

ALVES, João Emílio (Coord.), MARTINS Alexandre, MILHEIRO Eva e MARTINS Carla, Avaliação externa independente do projecto EQUAL "Potencializar recursos, valorizar e qualificar pessoas e organizações", Relatório final, Escola Superior de Educação de Portalegre, Dezembro de 2007 (documento policopiado).

CAPUCHA, Luís, ALMEIDA, João Ferreira de, PEDROSO, Paulo e SILVA José Vieira da, 1996, "Metodologias de avaliação: o estado da arte em Portugal", Sociologia-Problemas e Práticas, n. ${ }^{\circ}$ 22, Lisboa, CIES-ISCTE, pp. 9-27.

CAPUCHA, Luís, e outros, 1999, Metodologias de Avaliação de Intervenções Sociais, Ministério do Trabalho e Solidariedade, Módulos PROFISS, Lisboa.

COSTA, A. Firmino e GUERREIRO, Maria Dores, 1993, "Avaliação dos Impactos Sociais da Reabilitação Urbana", in Estruturas Sociais e Desenvolvimento, Actas do II. ${ }^{\circ}$ Congresso Português de Sociologia, Vol. I, Lisboa, APS e Editorial Fragmentos.

COSTA, António Firmino, e ALVES, João Emílio, 1996, “Avaliação processual em reabilitação urbana: conceitos e instrumentos" in Sociologia-Problemas e Práticas, n. ${ }^{\circ}$ 22, Lisboa, CIES-ISCTE, pp: 61-79.

ESEP, Projecto Potencializar recursos, valorizar e requalificar pessoas e organizações, 2004, (2004/EQUAL/A2/EE/141).
FERRÃO, João, 1996, "Avaliação comunitária de programas regionais: aspectos de uma experiência recente", Sociologia-Problemas e Práticas, n. ${ }^{\circ}$ 22, Lisboa, CIES-ISCTE, pp. 29-4l.

FIGUEIROA, David e PIMENTA, Manuel, 2005, "A Autoavaliação nos projectos EQUAL" in Cidades. Comunidades e Territórios, n. ${ }^{\circ} 11$, Lisboa, CET/ISCTE, pp. 13-22.

GABINETE DE GESTÃO EQUAL, 2001, Guia de Apoio às Parcerias de Desenvolvimento, Auto-avaliação dos projectos, Colecção Saber-Fazer n. ${ }^{\circ} 3$, Lisboa.

GABINETE DE GESTÃO EQUAL, 2001, Auto-avaliação dos projectos $-2 .{ }^{a}$ Fase, Colecção Saber-Fazer, Lisboa.

GABINETE DE GESTÃO EQUAL, 2005, Avaliação Independente dos Projectos Equal -Orientações, Lisboa.

GODET, Michel, 1993, Manual de Prospectiva Estratégica. Da Antecipação à Acção, Lisboa, Publicações D. Quixote.

GUERRA, Isabel, 2000, Fundamentos e Processos de uma Sociologia da Acção. O planeamento em Ciências Sociais, Cascais, Principia - Publicações universitárias e científicas.

MINISTÉRIO DO TRABALHO E SOLIDARIEDADE e IGFSS. 1999, Módulos Profissionais - Sistema modular de formação profissional para a solidariedade e segurança social, Lisboa. 